\title{
Large-scale interventions and programmes addressing nutrition- related chronic diseases and obesity: examples from 14 countries
}

\author{
Colleen Doak*
}

Department of Nutrition, University of North Carolina at Chapel Hill, 123 West Franklin Street, Chapel Hill, NC 27516-3997, USA

Developing countries are clearly facing a double burden of disease. The prevalences of overweight and obesity are rising among adults simultaneously with high rates of undernutrition among children ${ }^{1-7}$. Consequently, nutrition-related chronic diseases, such as cardiovascular disease and diabetes, are emerging as concerns in developing countries ${ }^{8}$. These concerns are combined with the continued need to address undernutrition and infectious disease. Overweight and obesity are increasing in Chile among low-income groups and poor communities ${ }^{9}$. There is a triple burden of disease in South Africa, described by Vorster $^{10}$. These are poverty-related infectious diseases, including HIV/AIDS, violence-related injuries and an increase in lifestyle-related non-communicable diseases. The burden of obesity and cardiovascular disease in the more developed regions of Brazil is also emerging among the poor ${ }^{11}$. As nutrition-related chronic diseases become more prevalent, limited resources will be further strained by the simultaneous cost of addressing infectious disease and undernutrition, while treating nutrition-related chronic diseases. Early prevention is essential in order to prevent the epidemic. As Reddy $^{8}$ states in this supplement, prevention is a necessary, cost-effective means of avoiding the high social, biological and economic costs of a treatment-based approach to nutrition-related chronic diseases. Thus, as a part of this meeting, we considered programmes in developing countries that have sought to intervene early to prevent obesity and nutrition-related chronic diseases.

\section{Participants}

There are few examples of large-scale interventions that focus on diet and activity patterns related to nutritionrelated chronic diseases in developing countries. Therefore, we queried the participants of the meeting for examples from their countries (Brazil, Chile, China, Cuba, Egypt, India, Iran, South Africa, South Korea, Malaysia, Mexico, Morocco, Thailand and Tanzania) of large-scale programmes to prevent obesity to change sedentary behaviours, or to address diet as related to chronic disease. This is the focus of this summary paper. Interventions and programmes related to undernutrition are not included. Only a few pilot projects that will eventually become larger-scale interventions and innovative, smaller studies are included. Since limitations of space preclude a comprehensive report, we summarise the key results.

\section{Large-scale and monitoring programmes}

Assessment of the extent of overweight, obesity and nutrition-related chronic diseases is critical to addressing the problem. Therefore, we first consider whether the countries represented in this meeting have established or are establishing large-scale programmes and/or monitoring systems. Monitoring systems include diachronic, nationally representative surveys that assess the prevalence of overweight, obesity or nutrition-related chronic diseases. A large-scale monitoring system is being built in Brazil. Chile, China, Cuba, Iran, India, South Africa, South Korea and Thailand have large-scale monitoring systems in place. There is a large-scale monitoring system in Morocco specifically for cardiovascular disease. The remaining countries - Egypt, Malaysia, Mexico and Tanzania - either have large-scale cross-sectional surveys that are not monitoring systems, or monitoring is through small surveys often related to research.

\section{School programmes}

Next we considered large-scale interventions or programmes oriented towards obesity and nutrition-related chronic diseases. Eight of the 14 countries represented have large-scale school-based interventions or programmes. Brazil has recently included, in the national school meals programme, the requirement that $70 \%$ of the foods be basic foods or minimally processed foods.

Chile has included more fruits and vegetables in the national school meals programme and is developing education programmes on nutrition and physical activity in schools. There is also a growing 'healthy schools' initiative focused on nutrition, physical activity, smoking cessation, environment and psychosocial risk factors that currently include more than 1000 schools. As described by Zhai et ll $^{12}$ in this supplement, the Ministry of Education in China has asked schools to increase time for physical activity. There have been large-scale nutrition education programmes in the schools in South Korea and dietitians are involved in the school meals programme. There is a multi-centre nutrition education programme in Malaysia. 
This is a research-oriented programme, and when completed, may provide insight into the effectiveness of such programmes. Pilot interventions in Mexico have been initiated to address child obesity, the goal of which is to increase physical activity and to promote knowledge of nutrition among children. There is a 'healthy schools' initiative in South Africa that includes a focus on obesity and nutrition-related chronic disease prevention. Finally, a school-based programme began in Thailand in September 2001. This programme, in regional primary and secondary schools, focuses on physical activity and a healthy diet.

\section{Workplace programmes}

Whereas schools are a convenient means of reaching children, the workplace is ideal for interventions reaching adults. It is not surprising to find that five countries have large-scale interventions or screening programmes at work sites because adults are the first group to be affected by nutrition-related chronic diseases. The healthcare system in Cuba for the prevention of nutrition-related non-communicable diseases has been extended to the workplace. Work sites in Chile are used for screening risk factors for non-communicable diseases. A large-scale intervention in India at multiple work sites incorporates exercise, changes in the cafeteria menus and family nutrition counselling. South Korea also has large-scale interventions or screening programmes at work sites that include regular health examinations as well as health and nutrition education and counselling. The promotion of physical activity in Thailand in the workplace is among the strategies of health promotion in the National Plan, although implementation of this varies by region. On a smaller scale, there are selected work site programmes in Tanzania that focus on exercise.

\section{Community-oriented programmes}

Although school-based and work site programmes target large numbers of individuals, seven countries have largescale studies focusing at the community level. There is a large-scale, multi-level, community-wide intervention in Brazil promoting physical activity through culturally appropriate means. This programme, known as Agita, is described in detail in this supplement by Matsudo et al. ${ }^{13}$. Within Brazil the programme is being extended to other communities, and the image and messages are adapted to make it culturally appropriate. In their paper focusing on Chile, Albala et al. ${ }^{9}$ describe the health promotion policy. This policy focuses on food, nutrition, physical activity and other risk factors for nutrition-related chronic diseases in an integrated way at the county and small community level. There are large-scale community education and health promotion programmes in China to reduce hypertension. Large-scale community programmes in Cuba promote physical activity, diet change and education for the prevention of nutrition-related chronic diseases. Health promotion related to nutrition-related chronic diseases in Mexico is in progress. In South Korea, nutrition and health services are available through the nation-wide community health centres. Dietitians have further supported the nutrition services of 32 test community health centres. This programme is expected to be expanded nation-wide. Finally, community programmes in Thailand focus on physical fitness and healthy eating for the elderly. With the exception of Thailand, which focuses on the elderly, these community interventions generally reach individuals of all ages.

\section{Other programmes}

Other large-scale interventions and programmes are good examples of the types of intervention that can be emulated elsewhere. There is an annual healthy lifestyle campaign in Malaysia. Although the specific focus changes each year, this event has included a focus on lifestyle related to nutrition-related chronic diseases. Such programmes increase awareness of non-communicable disease and related lifestyles, such as physical activity and diet. National campaigns in Thailand for nutrition-related chronic disease prevention focus on screening and management of nutrition-related chronic diseases such as hypertension and diabetes. All levels of the national healthcare system in Cuba address non-communicable diseases, including both prevention and control. A largescale initiative related to diabetes prevention in Iran includes screening, intervention, control and education. In the north-west province of South Africa, an intervention among farm dwellers seeks to bring both overweight and underweight individuals to optimal health. This type of programme is innovative and unique, and is an example of the kind of programme needed in communities facing both kinds of malnutrition. Another intervention in South Africa is a television soap opera series called Soul City. This programme targets low-income groups and includes health messages addressing both undernutrition and overweight, with a sister radio programme for those without access to television. Finally, the National Health Promotion Act of 1995 in South Korea included a call for diet and activity interventions to address nutrition-related chronic diseases and obesity prevention. Furthermore, nutrition specialists in South Korea have encouraged and promoted the traditional diet, which is low in fat and high in vegetables ${ }^{14,15}$. As described by Lee et $a l^{15}$ in this supplement, the consumption of local foods and agricultural products was encouraged to protect local farming. The government actively conserved the traditional diet through training housewives to cook the traditional cuisine ${ }^{14}$. South Korea provides an example of a country with a healthy traditional diet that was preserved through the joint efforts of dietitians and the government.

These programmes show that innovative interventions 
are addressing diet-related chronic diseases in many of the 14 countries represented at the Bellagio meeting. The proactive policy of South Korea to preserve the healthy traditional diet may explain why that country has not experienced the levels of obesity and overweight that would otherwise have been expected. The example of Agita in Brazil provides a theoretical framework and scientific model for interventions related to physical activity. The South Africa farm-dwellers initiative provides an example of a programme that addresses both undernutrition and overweight simultaneously. However, many countries have only recently become aware of nutritionrelated chronic diseases as a problem. In these countries, there is the potential to prevent sedentary behaviours and dietary patterns related to chronic disease risk before these behaviours become established. The most promising programmes are those that address the needs and concerns of the target communities using culturally appropriate methods and messages.

\section{References}

1 Crooks DL. Child growth and nutritional status in a highpoverty community in eastern Kentucky. Am. J. Phys. Anthropol. 1999; 109(1): 129-42.

2 Sawaya AL, Dallal G, Solymos GM, Souza M, Ventura ML, Roberts SB, et al. Obesity and malnutrition in a shantytown population in the city of Sao Paulo, Brazil. Obes. Res. 1995; 3(Suppl. 2): 107s-15s.

3 Ge K, Weisell R, Guo X, Cheng L, Ma H, Zhai F, et al. The body mass index of Chinese adults in the 1980s. Eur. J. Clin. Nutr. 1994; 48: S148-54.

4 Steyn K, Bourne L, Jooste P, Fourie JM, Rossouw K, Lombard
C. Anthropometric profile of a black population of the Cape Peninsula in South Africa. East Afr Med J. 1998; 75: 35-40.

5 Fitz PA. President's page: Food security - take your place at the advocates' table. J. Am. Diet. Assoc. 1998; 98(4): 469.

6 Drewnowski A, Popkin BM. The nutrition transition: new trends in the global diet. Nutr. Rev. 1997; 55(2): 31-43.

7 Florencio TM, Ferreira HS, de Franca AP, Cavalcante JC, Sawaya AL. Obesity and undernutrition in a very-lowincome population in the city of Maceio, northeastern Brazil. Br. J. Nutr. 2001; 86(2): 277-84.

8 Reddy KS. Cardiovascular diseases in the developing countries: dimensions, determinants, dynamics and directions for public health action. Public Health Nutr. 2002; 5: $231-7$.

9 Albala C, Vio F, Kain J, Uauy R. Nutrition transition in Chile: determinants and consequences. Public Health Nutr. 2002; 5: $123-8$.

10 Vorster HH. The emergence of cardiovascular disease during urbanisation of Africans. Public Health Nutr. 2002; 5: 23943.

11 Monteiro CA, Conde WL, Popkin BM. Is obesity replacing or adding to undernutrition? Evidence from different social classes in Brazil. Public Health Nutr. 2002; 5: 105-12.

12 Zhai F, Fu D, Du S, Ge K, Chen C, Popkin BM. What is China doing in policy-making to push back the negative aspects of the nutrition transition? Public Health Nutr. 2002; 5: 269-73.

13 Matsudo V, Matsudo S, Andrade D, Araujo T, Andrade E, de Oliveria LC, Braggion G. Promotion of physical activity in a developing country: the Agita São Paulo experience. Public Health Nutr. 2002; 5: 253-61.

14 World Health Organization (WHO). Physical Status: The Use and Interpretation of Anthropometry. Report of a WHO Expert Committee. WHO Technical Report Series 854. Geneva: WHO, 1995.

15 Lee M-J, Popkin BM, Kim S. The unique aspects of the nutrition transition in South Korea: the retention of healthful elements in their traditional diet. Public Health Nutr. 2002; 5: $197-203$ 